\title{
A modified high performance liquid chromatographic method for simultaneous quantification of skatole and indole in porcine plasma
}

\author{
Carl Brunius, Galia Zamaratskaia
}

Department of Food Science, BioCenter, Swedish University of Agricultural Sciences, Uppsala, Sweden

Received January 17, 2011

Accepted March 7, 2012

\begin{abstract}
A simplified high-performance liquid chromatography method to measure skatole and indole in porcine plasma without the use of acetonitrile was developed and validated in this study. The mobile phase consisted of water and methanol used in a gradient programme. Fluorescence detection was performed on the supernatant obtained from plasma after protein precipitation with $100 \%$ acetone. Limits of quantification were $0.5 \mathrm{ng} \cdot \mathrm{ml}^{-1}$ for skatole and $1.0 \mathrm{ng} \cdot \mathrm{ml}^{-1}$ for indole. Accuracy and precision had less than $12 \%$ deviation in the linear ranges $\left(0.5-256 \mathrm{ng} \cdot \mathrm{ml}^{-1}\right.$ and $\mathrm{R}^{2}=0.9999$ for skatole, $1.0-256 \mathrm{ng} \cdot \mathrm{ml}^{-1}$ and $\mathrm{R}^{2}=0.9999$ for indole). The correlation between plasma and serum concentrations was strong for skatole (slope $\left.=1.01, \mathrm{R}^{2}=0.999\right)$ and moderate for indole (slope $=0.65, \mathrm{R}^{2}=0.95$ ). Analysis of skatole in plasma was in good accordance with our previous acetonitrile-based method (slope $=0.91, \mathrm{R}^{2}=0.988$ ). The proposed method is suited for rapid routine analysis because of its high selectivity, accuracy and precision. Furthermore, it needs only simple sample preparation and the use of methanol instead of acetonitrile in the mobile phase. This method is of practical use to researchers in the field of boar taint.
\end{abstract}

Method validation, chromatography, indolic compounds, pig

Quantification of skatole and indole in biological tissues is of strong interest in the research on boar taint, an off flavour and off odour present in a proportion of meat from entire (uncastrated) male pigs. This off odour is mainly caused by skatole and androstenone and to a lesser extent indole, being deposited in the adipose tissue. Skatole and indole are produced in the large intestine of the pig by bacterial metabolism of tryptophan and further excreted via faeces or absorbed to the blood stream. Via the blood they are transported to various compartments, such as adipose tissue (causing boar taint) or liver (for further metabolism and excretion) (Zamaratskaia and Squires 2009). Skatole concentrations in adipose tissue and plasma are usually highly correlated (Tuomola et al. 1996; Zamaratskaia et al. 2004b). Thus, blood may be a suitable site for skatole and indole measurements because it can provide information about the contents of those compounds in adipose tissue. In fact, blood plasma is an increasingly used biological material to determine physiological status of the organism by quantification of plasma concentrations of various components (Blahova et al. 2007; Javed et al. 2009; Petrovic et al. 2009).

A number of high-performance liquid chromatographic (HPLC) methods have been developed for analyses of indolic compounds in plasma or serum (Lin et al. 1991; Claus et al. 1993; Tuomola et al. 1996; Zamaratskaia et al. 2004a). Due to the complexity of the matrix and possible interferences of analytes, lab-intensive and time-consuming cleanup procedures are often required prior to chromatographic separation. Alternatively, protein precipitating agents can be used to simplify sample preparation and minimize the total time and costs of analysis. The method previously used in our laboratory involved the use of acetonitrile for sample preparation and as organic modifier in the eluent (Zamaratskaia et al. 2004a). However, it would be beneficial to discontinue the use of acetonitrile because of its relatively high price and environmental impact compared to methanol. The global shortage of acetonitrile in 2009 further necessitated a modification of the existing HPLC

Address for correspondence:

Carl Brunius

Department of Food Science, BioCenter

Swedish University of Agricultural Sciences

Box 7057, SE-750 07 Uppsala, Sweden

Phone: +4618 671983

Fax: +46 18672995

E-mail: Carl.Brunius@slu.se

http://actavet.vfu.cz/ 
method. Therefore, the aim of the present study was to develop and validate a sensitive and reliable method to determine skatole and indole concentrations in porcine plasma. We also investigated the possibility of using serum as a sample material for skatole and indole analysis.

\section{Materials and Methods}

\section{Reagents}

Indole (2,3-benzopyrrole, $\geq 99 \%$ ), skatole (3-methylindole, $\geq 99 \%$ ) and tetrahydrofuran (HPLC-grade, $\geq 99.8 \%$ ) were obtained from Sigma Chemical Co (St. Louis, MO, USA). Acetic acid (analytical grade, $\geq 99.8$ ), acetone (analytical grade, $\geq 99.8$ ), isopropanol (HPLC-grade, $\geq 99.9 \%$ ) and methanol (HPLC-grade, $\geq 99.8 \%$ ) were obtained from Merck (Darmstadt, Germany). Ethanol ( $\geq 99.7 \%$ ) was obtained from Solveco (Stockholm, Sweden).

Plasma and serum samples

Blood samples were collected by jugular venipuncture from 20 adolescent boars of a crossbreed (Swedish Landrace sires $\times$ Swedish Yorkshire dams). To obtain plasma and serum, the blood was collected in vacutainer tubes with and without heparin, respectively. Plasma and serum were later obtained by centrifugation at $2000 \times g$ for $15 \mathrm{~min}$ at $4{ }^{\circ} \mathrm{C}$. For selectivity studies, plasma from 5 individual boars was used. For all other aspects of method development and validation, plasma was pooled. Samples from 11 boars were used to compare the concentrations of skatole and indole in serum and plasma.

Skatole and indole in 14 plasma samples were measured by two methods; the previous acetonitrile-based method (Zamaratskaia et al. 2004a) and the newly developed method.

The average water content in plasma and serum samples was $93 \%$ as determined by weighing before and after evaporation ( $\mathrm{n}=5$ for both plasma and serum).

Sample preparation

Plasma and serum

All samples were prepared in duplicates, if not stated otherwise. Precipitating solvent $(300 \mu 1)$ was added to equal amounts of plasma or serum. The samples were vortexed $(3 \times 5 \mathrm{~s})$, kept at $-20^{\circ} \mathrm{C}$ for 20 min and followed by centrifugation at $13,700 \mathrm{~g}$ for $20 \mathrm{~min}$ at $4{ }^{\circ} \mathrm{C}$. Clear supernatants were then transferred to HPLC vials for analysis.

Standards in aqueous solution

Aqueous standard solution samples were prepared in duplicates. The prepared concentrations were $7.5 \%$ higher than the corresponding plasma concentrations, accounting for a water content in the plasma of $93 \%$ $(1 / 0.93 \approx 1.075)$. Next, $300 \mu \mathrm{l}$ of acetone was added to $279 \mu \mathrm{l}(0.93 \times 300 \mu \mathrm{l})$ of aqueous standard solution. The samples were vortexed and then transferred to HPLC vials for analysis.

Chromatographic system

The HPLC system from Merck-Hitachi consisted of an on-line vacuum degasser (L-7612), pump (L-7100), autosampler (L-7200) with thermostated sample rack $\left(10^{\circ} \mathrm{C}\right)$, column oven $(\mathrm{L}-5025)$, fluorescence detector (FL7485), interface (D-7000) and D-7000 HPLC System Manager (v 4.1) software, used for system operation and analysis. The separation was achieved on a LiChrospher ${ }^{\circledR} 100$ RP-18 column (5 $\left.\mu \mathrm{m}, 250 \mathrm{~mm} * 4 \mathrm{~mm}\right)$, equipped with a guard column, operating at $40{ }^{\circ} \mathrm{C}$.

Two solvents were used in low pressure linear gradient mixing conditions: $0.1 \%(\mathrm{v} / \mathrm{v})$ aqueous solution of acetic acid (A) and methanol (B). The gradient profile was: $0.0 \min 55 \% \mathrm{~A} ; 0.1-0.5 \mathrm{~min} 25 \% \mathrm{~A} ; 0.6 \mathrm{~min} 55 \% \mathrm{~A}$, at a flow rate of $2.0 \mathrm{ml} / \mathrm{min}$. Excitation and detection wavelengths were set at $275 \mathrm{~nm}$ and $360 \mathrm{~nm}$, respectively. Photomultiplier voltage was set to medium. Samples $(50 \mu \mathrm{l})$ were injected at $10^{\circ} \mathrm{C}$.

Method validation

Method performance was evaluated with regard to selectivity, accuracy, precision, limit of quantification and linearity (Shah et al. 1992; Shah et al. 2000; FDA 2001; EC 2002; Thompson et al. 2002).

Selectivity

Matrix interactions in porcine plasma were investigated by careful inspection of chromatograms of plasma samples from 5 individual pigs to determine any interference of endogenous compounds with skatole and indole.

Accuracy and precision

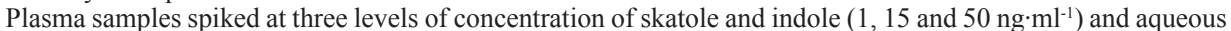
standards of corresponding concentrations (7.5\% higher) were prepared. Accuracy was determined by recovery analysis (comparing concentrations in spiked plasma to aqueous standards) and calculated as $\mathrm{R}=\left(\mathrm{C}_{\text {found }}-\mathrm{C}_{\text {blank }}\right)$ $/ \mathrm{C}_{\text {added }} * 100 \%$, where $\mathrm{C}_{\text {found }}$ and $\mathrm{C}_{\text {blank }}$ are the concentrations in spiked sample and non-spiked matrix (blank), respectively, and $\mathrm{C}_{\text {added }}$ is the added concentration. Precision was determined as relative standard deviations (RSD; expressed as a percentage) of multiple determinations of spiked plasma concentrations. The control samples were analysed $\times 8$ within the same run (intra-assay) and on 8 different days (inter-assay). 
Limit of quantification

Triplicate analyses of spiked plasma and corresponding aqueous standards of successively lower concentrations were performed. The limit of quantification was defined as the lowest concentration at which lack of accuracy or precision became a limiting factor $(>15 \%)$.

Linearity

Calibration curves for skatole and indole were constructed using 10 levels of concentration which covered the concentration ranges expected in our samples $\left(0.5,1,2,4,8,16,32,64,128\right.$ and $\left.256 \mathrm{ng} \cdot \mathrm{ml}^{-1}\right)$; spiked samples were used.

\section{Results}

\section{Sample preparation}

Five solvents were investigated for their use as plasma protein precipitating agents, namely methanol, ethanol, isopropanol (IPA), acetone and tetrahydrofuran (THF) (Blanchard 1981). The precipitating effects of methanol and ethanol were not sufficient. Within 5-10 min after sample preparation, these samples turned opaque. With the use of IPA and THF, substantial peak broadening occurred. Acetone demonstrated the best overall properties, with satisfactory precipitation and excellent peak shape. The potential disadvantage is its volatility. However, the sample rack was thermostated at $10{ }^{\circ} \mathrm{C}$, effectively diminishing evaporation. Based on the above observations, acetone was selected as precipitating agent for sample preparation.

\section{Validation for plasma samples}

\section{Selectivity}

Under the applied chromatographic conditions, indole and skatole eluted at 4.23 and 9.83 min, respectively. No interference with other peaks was observed. There was, however, a slight curvature in the baseline prior to the indole peak. A typical chromatogram is shown in Fig. 1.

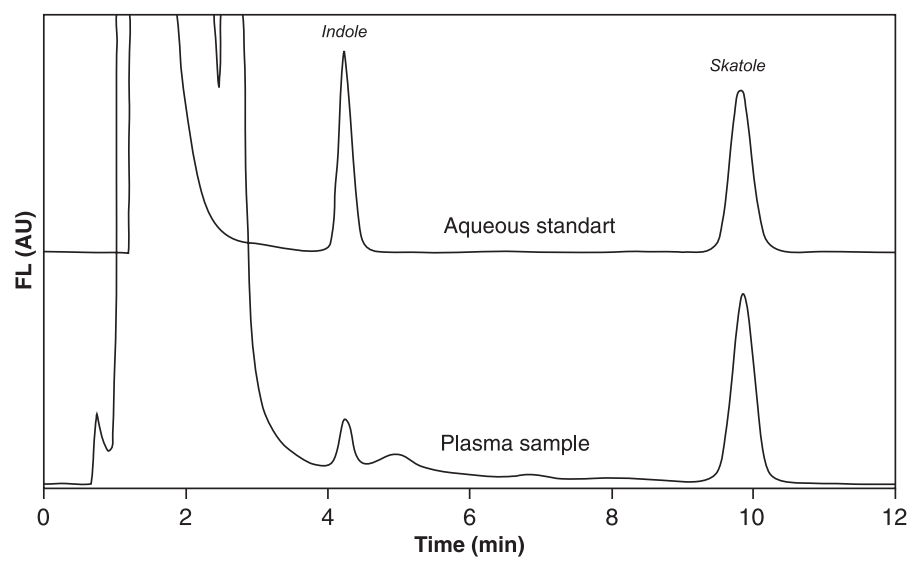

Fig. 1. Typical chromatograms of aqueous standard and plasma porcine sample. For clarity, indole and skatole peaks have been annotated in the chromatograms. Detector response was measured by fluorescence with excitation/emission at 275/360 nm.

$\mathrm{FL}$ - fluorescence, AU - arbitrary units

\section{Accuracy and precision}

Intra- and interassay values of recovery (accuracy) and RSD (precision) at low, medium and high concentrations are given in Table 1. Deviations were at satisfactory levels, with a tendency to increase at lower concentration, however never exceeding $12 \%$. 
Table 1. Intra- and interassay accuracy and precision at low, medium and high spiked concentrations of indole and skatole in porcine plasma, measured by recovery and relative standard deviation (RSD).

\begin{tabular}{|c|c|c|c|c|c|c|c|}
\hline & & \multicolumn{2}{|c|}{ Low (1 ng/ml) } & \multicolumn{2}{|c|}{ Medium (15 ng/ml) } & \multicolumn{2}{|c|}{ High (50 ng/ml) } \\
\hline & & Recovery & RSD & Recovery & RSD & Recovery & RSD \\
\hline \multirow[t]{2}{*}{ Intraassay } & Indole & $104.6 \%$ & $5.6 \%$ & $101.6 \%$ & $1.4 \%$ & $101.6 \%$ & $0.8 \%$ \\
\hline & Skatole & $108.4 \%$ & $11.9 \%$ & $102.6 \%$ & $1.2 \%$ & $102.4 \%$ & $0.7 \%$ \\
\hline \multirow[t]{2}{*}{ Interassay } & Indole & $93.9 \%$ & $9.7 \%$ & $102.0 \%$ & $2.8 \%$ & $105.1 \%$ & $3.4 \%$ \\
\hline & Skatole & $110.0 \%$ & $11.5 \%$ & $105.9 \%$ & $6.5 \%$ & $108.8 \%$ & $4.4 \%$ \\
\hline
\end{tabular}

\section{Limit of quantification}

The limits of quantification for skatole and indole were 0.5 and $1 \mathrm{ng} \cdot \mathrm{ml}^{-1}$, respectively. Below these concentrations, deviations in accuracy rapidly increased.

\section{Linearity}

Calibration curves for skatole and indole in plasma (spiked samples) are shown in Fig. 2. The linearity held true $\left(\mathrm{R}^{2}=0.9999\right)$ over the concentration ranges analysed for skatole $\left(0.5-256 \mathrm{ng} \cdot \mathrm{ml}^{-1}\right)$ and indole $\left(1-256 \mathrm{ng} \cdot \mathrm{ml}^{-1}\right)$.

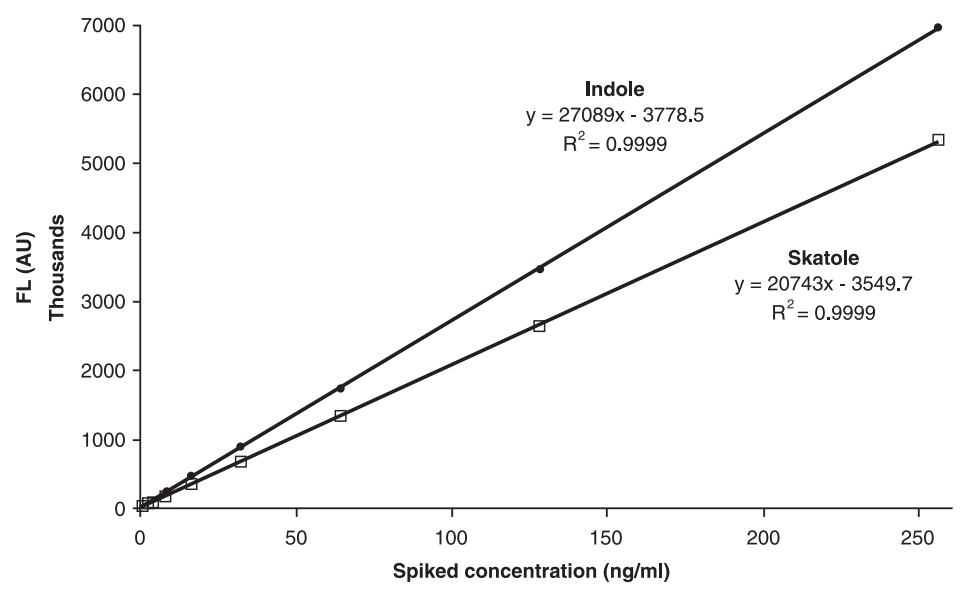

Fig. 2. Calibration curves for skatole $\left(0.5-256 \mathrm{ng} \cdot \mathrm{ml}^{-1}\right)$ and indole $\left(1-256 \mathrm{ng} \cdot \mathrm{ml}^{-1}\right)$ in porcine plasma. Detector response was measured by fluorescence with excitation/emission at 275/360 nm.

$\mathrm{FL}$ - fluorescence, AU - arbitrary units

Comparison between plasma and serum samples

Analyses of the individual matched plasma and serum samples demonstrated a high correlation for skatole (slope $=1.01, \mathrm{R}^{2}=0.999$, Fig. $3 \mathrm{a}$ ), and poorer correlation for indole (slope $=0.65, \mathrm{R}^{2}=0.95$, Fig. $3 \mathrm{~b}$ ). Inspection of the chromatograms for analysis in serum revealed a more pronounced curvature in the baseline around the indole peak (not shown), whereby the analytical results for indole in serum may be underestimated, especially at low concentrations.

Comparison with previous method

Analysis of skatole concentrations by the previous (Zamaratskaia et al. 2004a) and current modified methods revealed a strong correlation $\left(\mathrm{R}^{2}=0.988\right)$, with a slope close to unity and an intercept in the same order as the limit of quantification 

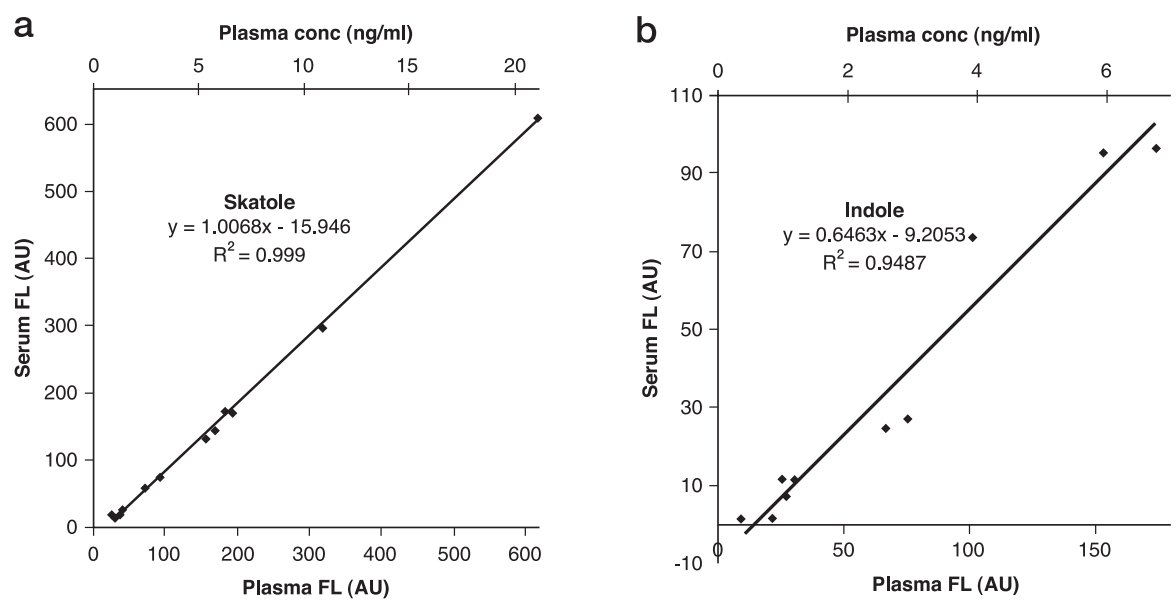

Fig. 3. Comparison of measured skatole (a) and indole (b) concentrations between individual matched porcine plasma and serum samples. Detector response was measured by fluorescence with excitation/emission at $275 / 360 \mathrm{~nm}$. $\mathrm{FL}$ - fluorescence, AU - arbitrary units

$\left(\mathrm{y}=0.9149 \mathrm{x}-0.6330 \mathrm{ng} \cdot \mathrm{ml}^{-1}\right.$, where $\mathrm{y}$ and $\mathrm{x}$ are the plasma concentrations of skatole in $\mathrm{ng} \cdot \mathrm{ml}^{-1}$ measured by the current and previous methods, respectively).

\section{Discussion}

There was no apparent need to establish an upper limit of linearity since $256 \mathrm{ng} \cdot \mathrm{ml}^{-1}$ of skatole is already above physiological concentrations. The highest concentration of skatole found in porcine plasma in our laboratory was $200 \mathrm{ng} \cdot \mathrm{ml}^{-1}$ (Zamaratskaia et al. 2004b).

Different specimens (plasma, serum or both) are routinely used by different research groups for the measurements of their compounds of interest. Plasma and serum are often considered equivalent for many analyses. However, measured levels of indolic compounds might be different in plasma than in serum due to interactions during and/or after coagulation. The observed decrease in slope from unity for indole measured in the two matrices implies that indole is lost from the serum during and/or after coagulation and that measurement of indole in serum does not reflect the concentration in plasma.

It should be emphasized that samples measured as described by Zamaratskaia et al. (2004a) had been stored for 7 years at $-20^{\circ} \mathrm{C}$ before being analysed with the current method. It is therefore highly likely that skatole is stable in plasma for at least 7 years at $-20^{\circ} \mathrm{C}$.

The modified HPLC method is specific, accurate and reproducible and can be successfully used to measure skatole and indole in porcine plasma without the use of acetonitrile. The limits of quantification are low enough to measure skatole and indole concentrations in porcine plasma. The use of serum for HPLC analyses of skatole gives equivalent results to plasma. The analysis of indole in porcine serum is not recommended. There is a good accordance in skatole analysis between our current modified and previous methods. Thus, this method is ideally suited for rapid routine analysis because of a simple sample preparation and use of methanol, which is less harmful than acetonitrile, in the mobile phase. Although the novelty of the proposed method is limited, we believe that this method will be of practical use to researchers in the field of boar taint. 


\section{Acknowledgements}

This study was funded by the Swedish Board of Agriculture.

\section{References}

Blahova J, Dobsikova R, Svobodova Z, Kalab P 2007: Simultaneous determination of plasma cortisol by high performance liquid chromatography and radioimmunoassay methods in fish. Acta Vet Brno 76: 59-64

Blanchard J 1981: Evaluation of the relative efficacy of various techniques for deproteinizing plasma samples prior to high-performance liquid-chromatographic analysis. J Chromatogr 226: 455-460

Claus R, Dehnhard M, Herzog A, Bernal-Barragan H, Giménez T 1993: Parallel measurements of indole and skatole (3-methylindole) in feces and blood plasma of pigs by HPLC. Livest Prod Sci 34: 115-126

EC (2002). Decision 2002/657/EC. Official Journal of the European Communities. L221: 8-36: Commission of the European Communities

FDA (2001). Guidance for industry: Bioanalytical method validation Rockville, MD: US Department of Health and Human Services, Food and Drug Administration, Center for Drug Evaluation and Research

Javed I, Iqbal Z, Zia ur R, Khan MZ, Muhammad F, Aslam B, Sandhu MA, Sultan JI 2009: Disposition kinetics and optimal dosage of ciprofloxacin in healthy domestic ruminant species. Acta Vet Brno 78: 155-162

Lin RS, Orcutt MW, Patterson JA, Judge MD 1991: Serum skatole detection using gas chromatography and high performance liquid chromatography. Meat Sci 30: 33-40

Petrovic V, Novotny J, Hisira V, Link R, Leng L, Kovac G 2009: The impact of suckling and post-weaning period on blood chemistry of piglets. Acta Vet Brno 78: $365-371$

Shah VP, Midha KK, Dighe S, McGilveray IJ, Skelly JP, Yacobi A, Layloff T, Viswanathan CT, Cook CE, McDowall RD, Pittman KA, Spector S, Albert KS, Bolton S, Cook CE, Dighe S, Dobrinska M, Doub W, Eichelbaum M, Findlay JWA, Gallicano K, Garland W, Hardy DJ, Hulse JD, Karnes HT, McDowall RD, Lange R, Layloff T, Mason WD, McKay G, McGilveray IJ, Midha KK, Ormsby E, Overpeck J, Pittman KA, Plattenberg HD, Shah VP, Shiu G, Sitar D, Skelly JP, Sorgel F, Spector S, Stewart JT, Viswanathan CT, Yacobi A, Yuh L 1992: Analytical methods validation - Bioavailability, bioequivalence and pharmacokinetic studies. Pharmaceut Res 9: 588-592

Shah VP, Midha KK, Findlay JWA, Hill HM, Hulse JD, McGilveray IJ, McKay G, Miller KJ, Patnaik RN, Powell ML, Tonelli A, Viswanathan CT, Yacobi A 2000: Bioanalytical method validation - A revisit with a decade of progress. Pharmaceut Res 17: 1551-1557

Thompson M, Ellison SLR, Wood R 2002: Harmonized guidelines for single-laboratory validation of methods of analysis - (IUPAC technical report). Pure Appl Chem 74: 835-855

Tuomola M, Vahva M, Kallio H 1996: High-performance liquid chromatography determination of skatole and indole levels in pig serum, subcutaneous fat, and submaxillary salivary glands. J Agr Food Chem 44: $1265-1270$

Zamaratskaia G, Babol J, Andersson H, Lundström K 2004a: Plasma skatole and androstenone levels in entire male pigs and relationship between boar taint compounds, sex steroids and thyroxine at various ages. Livest Prod Sci 87: 91-98

Zamaratskaia G, Babol J, Madej A, Squires EJ, Lundström K 2004b: Age-related variation of plasma concentrations of skatole, androstenone, testosterone, oestradiol-17 beta, oestrone sulphate, dehydroepiandrosterone sulphate, triiodothyronine and IGF-1 in six entire male pigs. Reprod Domest Anim 39: 168-172

Zamaratskaia G, Squires EJ 2009: Biochemical, nutritional and genetic effects on boar taint in entire male pigs. Animal 3: 1508-1521 